\title{
Muito além de um dente: ocorrência de hidatódios nos dentes foliares de Hydrocotyle asterias Cham. \& Schltdl. (Araliaceae Juss.) ${ }^{1}$
}

\author{
Alex Batista Moreira Rios ${ }^{2,3}$ e (1) Valdnéa Casagrande Dalvi ${ }^{2}$
}

Recebido: 17.07.2019; aceito: 25.03 .2020

Como citar: Rios, A.B.M. \& Dalvi, V.C. 2020. Muito além de um dente: ocorrência de hidatódios nos dentes foliares de Hydrocotyle asterias Cham. \& Schltdl. (Araliaceae Juss.). Hoehnea 47: e782019. http://dx.doi.org/10.1590/2236-8906$78 / 2019$.

ABSTRACT - (Much more than just a tooth: occurrence of hydathodes in the leaf teeth of Hydrocotyle asterias Cham. \& Schltdl. (Araliaceae Juss.)). Although Araliaceae has many species with toothed leaf margins, the anatomical structure of these projections hasnever been investigated. The objective of this study was to characterize the anatomy of the leaf teeth of Hydrocotyle asterias Cham. \& Schltdl., a representative of this family. Fragments of the leaf teeth were processed according to the usual techniques for optical microscopy (diaphanization and paradermal cuts) and scanning electron microscopy. The leaf tooth of $H$. asterias consists of hydathodes whose size, shape, and space between teeth vary among the different stages of leaf development. They have unstratified epidermis composed of isodiametric cells with slightly thickened walls, thin cuticle, and stomata concentrated at the apical region. Vascularization is composed of xylem that projects to the epithem. This study presents the first data on the anatomical structure of the leaf teeth of the Araliaceae family and expands the knowledge about the hydathodes associated with leaf teeth.

Keywords: anatomy leaf, gland, leaf projections

RESUMO - (Muito além de um dente: ocorrência de hidatódios nos dentes foliares de Hydrocotyle asterias Cham. \& Schltdl. (Araliaceae Juss.)). Embora Araliaceae possua muitas espécies contendo folhas com margens denteadas, a estrutura anatômica dessas projeções nunca foi investigada. Assim, este estudo teve como objetivo caracterizar a anatomia dos dentes foliares de Hydrocotyle asterias Cham. \& Schltdl., representante desta família. Fragmentos do limbo foliar com dentes marginais foram processados conforme técnicas usuais para microscopia óptica (diafanização, cortes paradérmicos e testes histoquímicos) e microscopia eletrônica de varredura. Os dentes de H. asterias consistem em hidatódios, cujo tamanho, formato e espaço entre os dentes variam nos diferentes estágios de desenvolvimento da folha. Eles apresentam epiderme uniestratificada, composta por células isodiamétricas com paredes levemente espessadas, cutícula delgada e estômatos concentrados na região apical. A vascularização é composta por xilema que se projeta até o epitema. Este estudo apresenta as primeiras informações sobre a estrutura anatômica dos dentes foliares da família Araliaceae e amplia o conhecimento sobre os hidatódios localizados nos dentes foliares.

Palavras-chave: anatomia foliar, glândula, projeções da folha

\section{Introdução}

Dentes foliares podem ser definidos como projeções marginais do limbo que apresentam heterogeneidade quanto ao formato, tamanho, constituição e disposição na margem foliar (Hickey \& Wolfe 1975, Ash et al. 1999). São bastante comuns nas Angiospermas e suas características possuem grande relevância taxonômica e filogenética (Stevens 2017). Essas projeções se diferenciam por meio da distância entre a base e o ápice do dente; formato do dente e do ápice; espessura e distribuição das nervuras no interior da projeção; quantidade, tamanho e espaçamento entre os dentes ao

1. Parte da Dissertação de Mestrado do primeiro Autor

2. Instituto Federal de Educação, Ciência e Tecnologia Goiano, Campus Rio Verde, Rodovia Sul Goiana, Km 01, Zona Rural, 75901-970 Rio Verde, GO, Brasil

3. Autor para correspondência: alexriosbio1991@gmail.com 
longo da margem foliar; e o tipo de glândula que pode ocorrer na região apical (Ellis et al. 2009). Considerando essas características, já foram descritos 15 tipos diferentes de dentes foliares: begonioide, clorantoide, cucurbitoide, cunonioide, dilenioide, espinoso, malvoide, monimioide, platanoide, rosoide, salicoide, teoide, tipo fothergillia, urticoide e violoide (Hickey \& Wolfe 1975). Nesse sistema de classificação, apenas os dentes espinoso, malvoide e urticoide foram considerados destituídos de glândulas.

Três tipos de glândulas foram descritas associadas aos dentes foliares: coléteres, hidatódios e nectários. Coléteres já foram confirmados nos dentes foliares de espécies das famílias Aquifoliaceae (Gonzalez \& Tarragó 2009), Euphorbiaceae (Vitarelli et al. 2015), Lecythidaceae (Paiva 2012), Rosaceae (Chin et al. 2013) e Salicaceae (Fernandes et al. 2016). Hidatódios foram reportados para Asteraceae (Castro, Leitão-Filho \& Monteiro 1997, Melo-de-Pinna 2004, Milan, Hayashi \& Appezzato-da-Glória 2006), Chloranthaceae (Field et al. 2005) e Salicaceae (Thadeo, Azevedo \& Meira, 2014). Nectários extraflorais foram encontrados em Malvaceae (Leitão et al. 2002), Rosaceae (So 2004) e Salicaceae (Thadeo et al. 2008).

Araliaceae Juss. é uma família botânica amplamente distribuída nas regiões tropicais e temperadas, reunindo cerca de 43 gêneros e 1450 espécies constituídas por arbustos, árvores, ervas perenes, lianas lenhosas e algumas epífitas (Fiachi \& Pirani 2005, Souza \& Lorenzi 2012, Stevens 2017, Souza et al. 2018). No entanto, apesar de muitas espécies dessa família possuírem dentes foliares (Judd et al. 2009), a natureza anatômica dessas projeções não havia sido investigada para esse grupo.

Hydrocotyle asterias Cham. \& Schltdl. é uma espécie herbácea endêmica dos campos rupestres do Estado de Minas Gerais (Flora do Brasil 2020). Os representantes dessa espécie apresentam folhas com margens irregularmente serreadas a serrilhadas (Côrrea \& Pirani 1999), onde são encontrados dentes foliares (figura $1 \mathrm{a}-\mathrm{b}$ ). Assim, esse trabalho teve como objetivo investigar a constituição dos dentes foliares de $H$. asterias caracterizando sua morfologia e anatomia.

\section{Material e Métodos}

Cinco indivíduos de H. asterias foram coletados em um trecho de Campo Rupestre localizado entre os municípios de Morro do Pilar e Conceição do Mato Dentro, Estado de Minas Gerais, Brasil (19¹3'12,03”S 4329'51,33”W), no mês de janeiro de 2017 (figura 1 a). O material testemunho foi depositado no Herbário do Instituto Federal Goiano, Campus Rio Verde (IFRV).
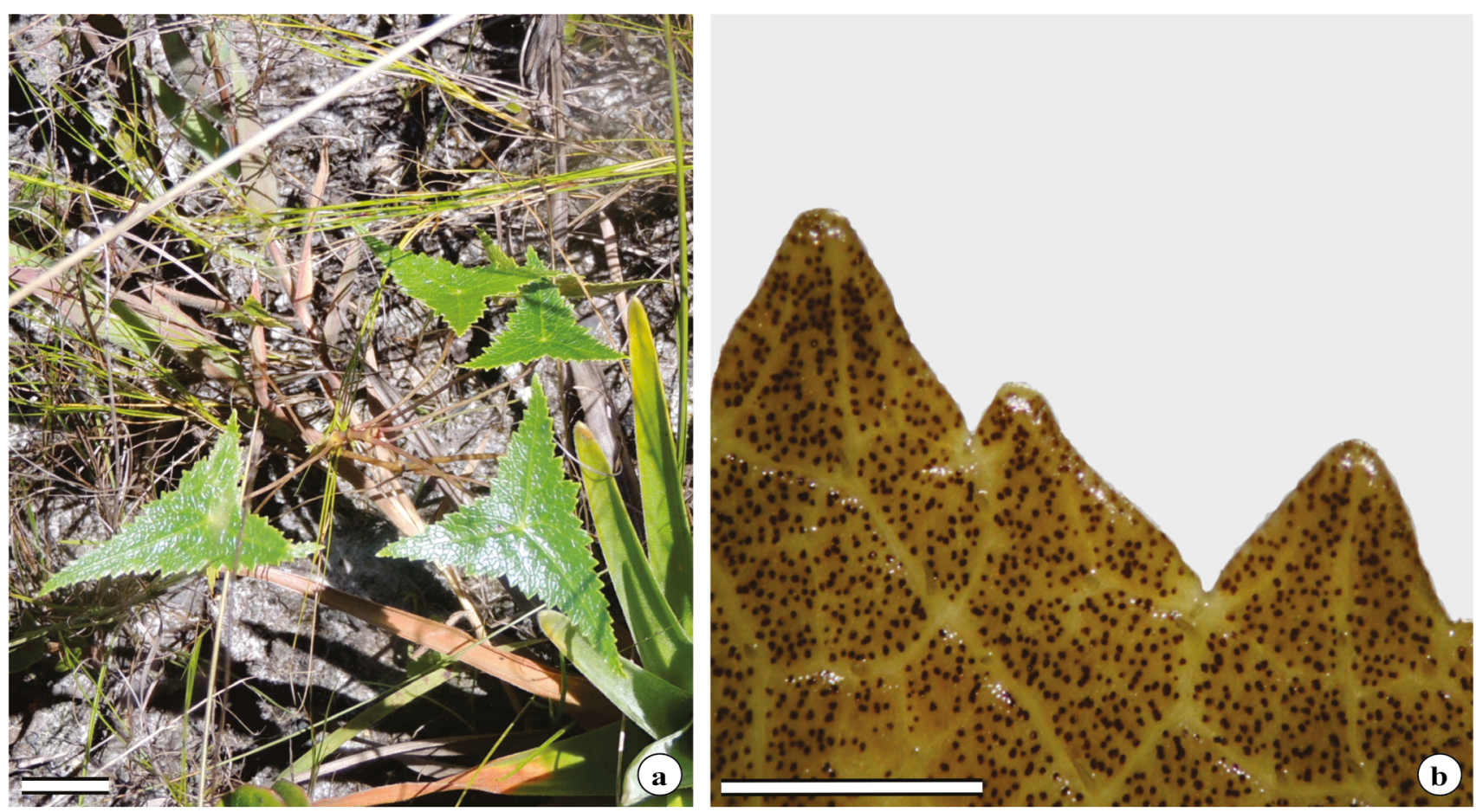

Figura 1. Dentes foliares de Hydrocotyle asterias Cham. \& Schltdl. (Araliaceae). a. Indivíduos em área de campo rupestre. b. Aspecto morfológico dos dentes foliares. Barras de escala: a. $10 \mathrm{~cm}$; b. $1 \mathrm{~cm}$.

Figure 1. Hydrocotyle asterias Cham. \& Schltdl. (Araliaceae) leaf teeth. a. Plants in rocky field. b. Morphological aspect of leaf teeth. Scale bars: a. $10 \mathrm{~cm} ;$ b. $1 \mathrm{~cm}$. 
Material examinado: Brasil: MinAS geRAIS: Morro do Pilar, Conceição do Mato Dentro, bifurcação entre Morro do Pilar e Conceição do Mato Dentro, área de campo rupestre úmido, Serra do Cipó, 29-I-2017, A.B.M. Rios \& V.C. Dalvi 797, $1188,1189,1190$ e 1191 IFRV.

Amostras de margens foliares denteadas em três estágios de desenvolvimento (folha jovem, folha adulta e folha senescente) foram coletadas, fixadas em FAA (formalina 37\%, ácido acético e álcool a 70\%; 1:1:18 v:v:v) e armazenadas em álcool etílico 70\% (Johansen 1940). Para a caracterização da estrutura anatômica dos dentes, parte das amostras fixadas foi submetida ao processo de diafanização (Arnott 1959), e as lâminas foram montadas com Permount (Fischer Scientific, Fair Lawn, NJ, Estados Unidos). Fragmentos de margens foliares contendo dentes, selecionados com auxílio do estereomicroscópio Bel Photonix (modelo WF10X, Alemanha), foram desidratados em série etílica e incluídos em historesina (Historesin, Leica Instruments, Heidelberg, Alemanha). Cortes paradérmicos da folha com $7 \mu \mathrm{m}$ foram obtidos com o uso do micrótomo rotativo (Modelo 1508R, Logen Scientific, Alemanha) e com a utilização de navalhas de aço descartáveis de baixo perfil. Os cortes foram corados com azul de toluidina pH 4,7 (O`Brien et al. 1964) e montados em Permount (Fischer Scientific, Fair Lawn, NJ, Estados Unidos). As observações das lâminas seguidas das descrições anatômicas foram realizadas com o uso de microscópio óptico (modelo LEICA DM500, Alemanha) e os registros fotográficos foram realizadas no fotomicroscópio Olympus (modelo BX61, Japão) equipado com sistema de captura de imagens e câmera DP-72.

Para estudar a micromorfologia dos dentes, fragmentos das amostras foliares armazenados em etanol $70 \%$ foram desidratados em série etílica e levados para secagem ao ponto crítico (Bozzola \& Russel 1992), utilizando-se o equipamento CPD 020; Bal-Tec, Balzers, Liechtenstein. Posteriormente, as amostras foram fixadas em stubs com uso de fita dupla face e metalizadas no sistema para deposição de filmes de ouro no equipamento Sputter, Denton Vacuum, Desk V. A observação e a captura de imagens foram realizadas em microscópio eletrônico de varredura (MEV), Jeol, JSM - 6610, equipado com EDS, Thermo scientific NSS Spectral Imaging.

\section{Resultados}

Os dentes foliares de Hydrocotyle asterias Cham. \& Schltdl. apresentam coloração verde claro e manchas marrons (figura $1 \mathrm{~b}$ ). Tais dentes possuem formatos variados e distribuição irregular na margem da folha (figura $1 \mathrm{~b}$ ). $\mathrm{O}$ tamanho dos dentes e o espaçamento entre eles aumentam à medida em que a lâmina foliar se expande (figura $2 \mathrm{a}-\mathrm{c}$ ).
Anatomicamente, os dentes foliares de $H$. asterias consistem em hidatódios. Ao contrário do que ocorre ao longo da lâmina foliar (figura 2 a), foi observado que a superfície dos dentes é destituída de tricomas (figura 2 b-c), sendo que os estômatos se concentram na região apical da glândula (figura 2 b-e). A epiderme é uniestratificada, constituída por células isodiamétricas, que apresentam paredes levemente espessadas e cutícula delgada (figura 3 a). O epitema se estende até as proximidades da base do hidatódio e possui células que se diferem nitidamente das células do parênquima circundante à glândula (figura 3 b). As células epitemáticas são menores, de formato variável, e o citoplasma é mais denso (figura $3 \mathrm{c}$ ).

Feixes vasculares se projetam da base do dente até a região das células epitemáticas (figura $3 \mathrm{~d}$ ), formando duas nervuras laterais e uma central, que se conectam na base do hidatódio (figura 3 e). A vascularização é constituída exclusivamente por xilema e ficam envolvidos lateralmente por células parenquimáticas comuns (figura 3 e).

\section{Discussão}

Considerando o formato do dente, a disposição dos feixes vasculares e associação com uma glândula hidatódio, os dentes foliares de Hydrocotyle asterias Cham. \& Schltdl. foram reconhecidos como do tipo clorantoide. De acordo com a classificação dos dentes foliares proposta Hickey $\&$ Wolfe (1975), esse tipo de dente geralmente possui três feixes vasculares, um feixe central e dois feixes periféricos, que se aglutinam nas proximidades de uma glândula com forma variável e não decídua.

Apesar da ocorrência generalizada em vários grupos de Angiospermas, do registro de hidatódios em sua constituição e de seu significado taxonômico (Todzia \& Keating 1991, Feild et al. 2005, APG IV 2016, Stevens 2017), os dentes clorantoides são pouco estudados do ponto de vista anatômico. Isto pode estar relacionado ao fato de que a maioria dos autores consideram a constituição dos dentes foliares similar a da lâmina foliar, uma vez que qualquer morfotipo de dente consiste em uma continuidade da folha (Ash et al. 1999). Desta forma, as características anatômicas descritas para a folha são atribuídas para os dentes, condição que inviabiliza uma correta compreensão da organização estrutural, funcional, evolutiva e ecológica dessa projeção da margem foliar.

Estudos que investigaram a anatomia dos dentes foliares evidenciaram que a associação destes com estruturas secretoras, suscitando novas indagações inerentes ao papel taxonômico e ecológico dos dentes foliares (Thadeo, Azevedo \& Meira 2014, Fernandes et al. 2016). Nectários extraflorais com tricomas nectaríferos foram encontrados no ápice dos dentes foliares de Triumfetta semitriloba Jacq. (Malvaceae), onde foi observado que a atividade secretora 

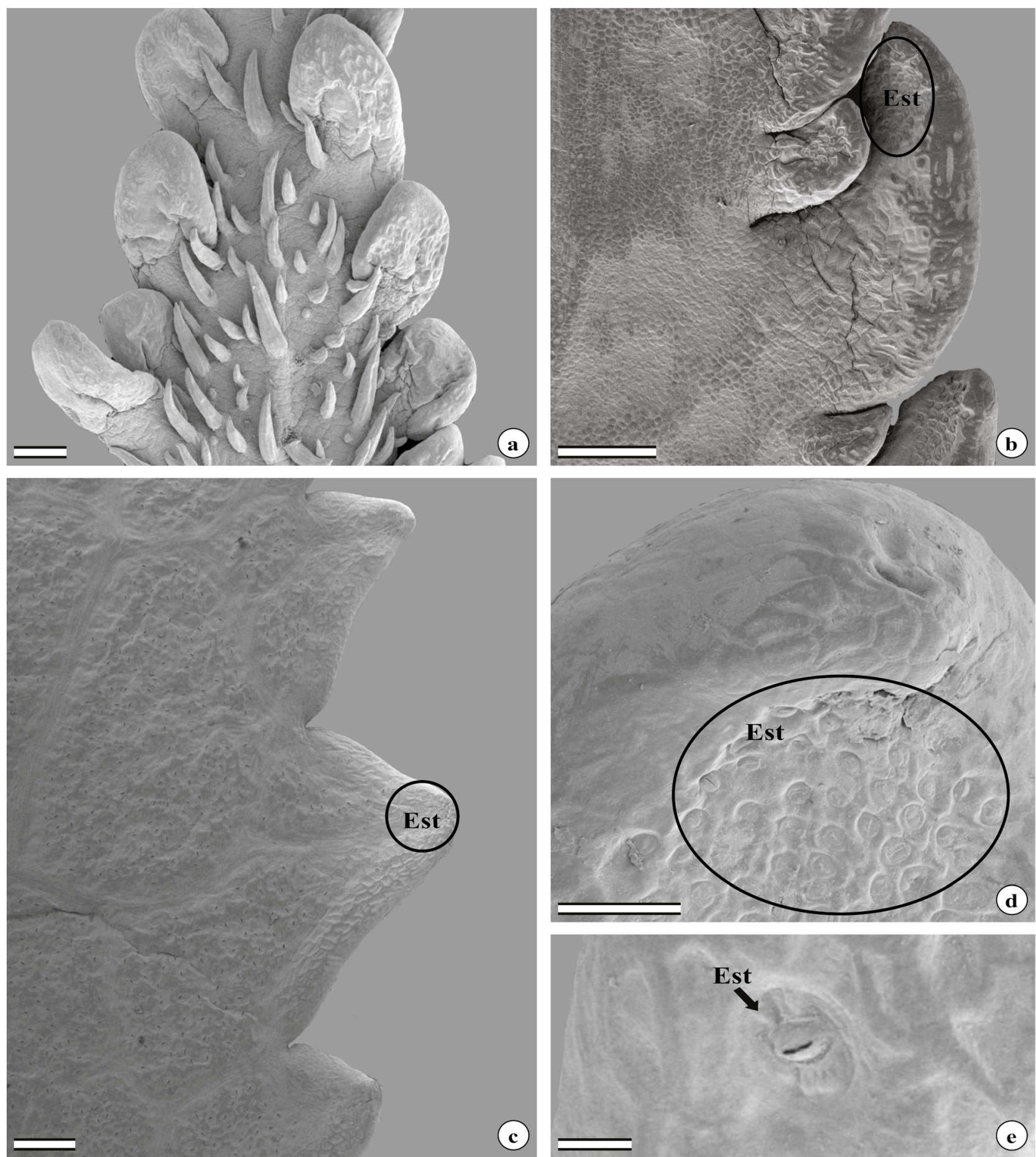

c)

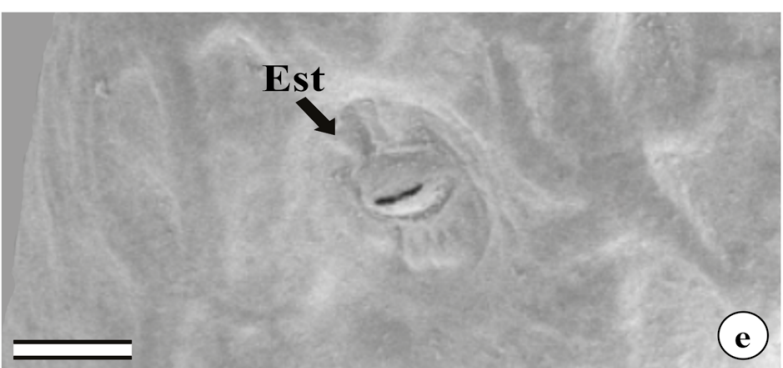

Figura 2. Microscopia eletrônica de varredura dos dentes foliares de Hydrocotyle asterias Cham. \& Schltdl. (Araliaceae). a. Folha jovem. b. Formato dos dentes foliares em detalhe. c. Dentes foliares da folha adulta. d. Localização dos estômatos (Est). e. Estômato (Est) em detalhe. Barras de escala: a. $200 \mu \mathrm{m}$; b. $100 \mu \mathrm{m}$; c. $500 \mu \mathrm{m}$; d. $50 \mu \mathrm{m}$; e. $50 \mu \mathrm{m}$.

Figure 2. Scanning electron microscopy of Hydrocotyle asterias Cham. \& Schltdl. (Araliaceae) leaf teeth. a. Young leaf. b. Leaf teeth shape in detail. c. Leaf teeth of the adult leaf. d. Stomata localization (Est). e. Stomata (Est) in detail. Scale bars: a. $200 \mu \mathrm{m} ; \mathrm{b} .100 \mu \mathrm{m}$; c. $500 \mu \mathrm{m} ;$ d. $50 \mu \mathrm{m} ;$ e. $50 \mu \mathrm{m}$. 


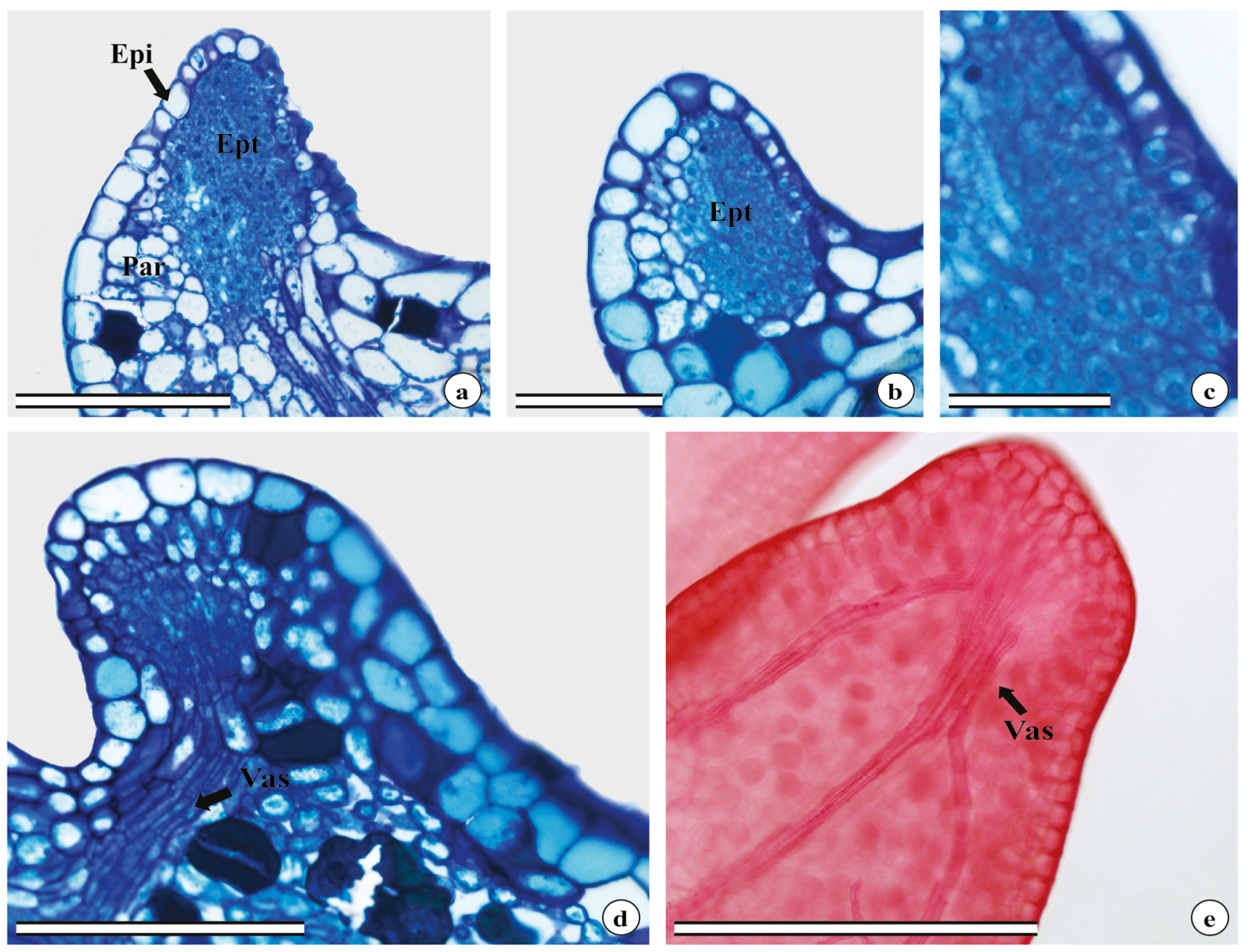

Figura 3. Estrutura dos dentes foliares de Hydrocotyle asterias Cham. \& Schltdl. (Araliaceae). a. Detalhe da Epiderme (Epi), Epitema (Ept) e Parênquima (Par). b. Região do epitema (Ept). c. Detalhe das células epitemáticas. d. Vascularização (Vas) do hidatódio em microscopia de luz. e. Distribuição das nervuras no dente foliar. Barras de escala: a. $200 \mu \mathrm{m}$; b. $100 \mu \mathrm{m}$; c. $50 \mu \mathrm{m}$; d. $5200 \mu \mathrm{m}$; e. $500 \mu \mathrm{m}$.

Figure 3. Structure of leaf teeth from Hydrocotyle asterias Cham. \& Schltdl. (Araliaceae). a. Epidermis distribution (Epi), Epithem (Ept) e Parenchyma (Par). b. Epithem region (Ept). c. Epithem cells. d. Hydathode vascularization (Vas) under light microscope. e. Leaf teeth vein distribution. Scale bars: a. $200 \mu \mathrm{m}$; b. $100 \mu \mathrm{m}$; c. $50 \mu \mathrm{m}$; d. $5200 \mu \mathrm{m}$; e. $500 \mu \mathrm{m}$.

dessas glândulas pode interferir na interação da planta com fungos e formigas (Leitão et al. 2002).

Em Salicaceae, estudos anatômicos revelaram que, de acordo com a espécie, o dente teoide pode ocorrer associado à coléteres ou hidatódios, apresentando características de importante aplicação taxonômica (Thadeo, Azevedo \& Meira 2014, Fernandes et al. 2016). Esses dados ratificam a importância de se conhecer a composição dos dentes foliares, uma vez que podem amplificar o entendimento estrutural e funcional dessa região da folha para as plantas (Melo-de-Pinna 2004, Nicolas \& Plunkett 2009).

Apesar de muitas espécies de Araliaceae possuírem folhas com margens denteadas (Judd et al. 2009), a natureza anatômica dos dentes foliares não havia sido investigada. Nesse sentido, a confirmação do hidatódio como estrutura secretora associada ao dente clorantoide, realizada nesse estudo, acrescenta um novo significado dessa projeção foliar para a família Araliaceae e para o gênero Hydrocotyle em particular. Além disso, tendo em vista que a ocorrência de estruturas secretoras em Araliaceae é pouco relatada, o registro de hidatódio para $H$. asterias abre perspectivas para que investigações referentes a glândulas sejam desenvolvidas nessa família.

O fenômeno da gutação não foi observado em $H$. quinqueloba durante as excursões em campo. Embora os hidatódios iniciem sua atividade secretora mesmo antes do órgão em que estão inseridos completar seu desenvolvimento (Sperry, 1983), a capacidade de observar a gutação em condições naturais é limitada para muitas espécies, pois esse processo pode ocorrer em apenas alguns estágios de 
desenvolvimento da lâmina foliar ou sob circunstâncias ambientais específicas pouco observadas (Takeda et al. 1991, Silva et al. 2014). Experimentos realizados para estudar os efeitos da gutação evidenciam que o hidatódio desempenha outras funções além de eliminar excedente aquoso da folha (Singh 2014).

Em ambientes costeiros onde pode haver limitação de água causada pelo estresse salino, já foram encontrados hidatódios coletando água do nevoeiro, realizando um fluxo hídrico inverso entre poro e vascularização para que as plantas possam crescer e se desenvolver (Burgess $\&$ Dawson 2004). Além disso, alguns estudos revelaram que o exsudado da gutação pode conter compostos como alcaloides, que atuam na defesa contra predadores, parasitas e plantas competidoras (Koulman et al. 2007, Shepherd \& Wagner 2007, Singh 2014).

Em relação aos Campos Rupestres, embora seja evidente que variáveis ambientais como temperatura, umidade, intensidade luminosa e drenagem do solo possam interferir na capacidade da comunidade vegetal de se estabelecer nessas formações (Côrrea \& Pirani 1999, Conceição \& Pirani, 2005, Guilherme 2011, Vasconcelos 2014), o funcionamento dos hidatódios é pouco conhecido. Desta forma, estudos posteriores devem investigar a atividade secretora dessas glândulas associadas aos dentes de plantas dessas regiões, como H. asterias.

\section{Conclusões}

Os resultados deste estudo constituem as primeiras informações sobre a morfologia e anatomia dos dentes foliares de Hydrocotyle asterias Cham. \& Schltdl. e para a família Araliaceae. A caracterização dessas projeções também confirmou a ocorrência de hidatódios como glândulas associadas a esses dentes. Além disso, os dados ampliam o conhecimento a respeito do dente clorantoide e da variação estrutural dos hidatódios. Futuros estudos com foco nos dentes foliares em Araliaceae poderão elucidar o papel taxonômico, funcional e filogenético dessas estruturas da margem foliar tão comuns e pouco conhecidas nessa família.

\section{Agradecimentos}

Agradecemos à Coordenação de Aperfeiçoamento de Pessoal de Nível Superior (CAPES), pela bolsa concedida ao primeiro Autor; aos Laboratórios de Anatomia Vegetal e de Sistemática e Ecologia Vegetal do Instituto Federal de Ciência, Educação e Tecnologia Goiano campus Rio Verde, pela infraestrutura ofertada para se realizar os estudos anatômicos; ao Núcleo de Microscopia e Microanálise (NMM) da Universidade Federal de Viçosa (UFV) e ao Centro Regional de Desenvolvimento de Tecnologias e Inovação (CRTI) da Universidade Federal de Goiás (UFG), pelas análises de Microscopia Eletrônica de Varredura.

\section{Literatura citada}

APG IV. 2016. An update of the Angiosperm Phylogeny Group classification for the orders and families of flowering plants: APG IV. Botanical Journal of the Linnean Society 181: 1-20.

Arnott, H.J. 1959. Leaf clearings. Turtox News 37: 192-194.

Ash, A., Ellis, B., Hickey, L.J., Johnson, K., Wilf, P. \& Wing, S. 1999. Manual of Leaf Architecture - morphological description and categorization of dicotyledonous and net-veined monocotyledonous angiosperms by leaf architecture. Washington, Smithsonian Institution.

Bozzola, J.J. \& Russel, L.L.D. 1992. Electron microscopy. Boston, Jones and Bartlett Publishers.

Burgess, S.S.O. \& Dawson, T.E. 2004. The contribution of fog to the water relations of Sequoia sempervirens (D. Don): foliar uptake and prevention of dehydration. Plant, Cell and Environment 27: 1023-1034.

Castro, M.M, Leitão-Filho, H.F. \& Monteiro W.R. 1997. Utilização de estruturas secretoras na identificação dos gêneros de Asteraceae de uma vegetação de cerrado. Revista Brasileira de Botânica 20: 163-174.

Chin, S.-W., Lutz, S., Wen, J. \& Potter, D. 2013. The bitter and the sweet: inference of homology and evolution of leaf glands in Prunus (Rosaceae) through anatomy, micromorphology, and ancestral- character state reconstruction. International Journal of Plant Sciences 174: 27-46.

Conceição, A.A. \& Pirani, J.R. 2005. Delimitação de habitats em campos rupestres na Chapada da Diamantina, Bahia: substratos, composição florística e aspectos estruturais. Boletim de Botânica da Universidade de São Paulo 23: 85-111.

Corrêa, I.P. \& Pirani, J.R. 1999. Flora da Serra do Cipó, Minas Gerais: Umbelliferae (Apiaceae). Boletim de Botânica da Universidade de São Paulo 18: 61-68.

Ellis, B., Daly, D.C., Hickey, L.J., Johnson, K.R., Mitchell, J.D., Wilf, P. \& Wing, S.L. 2009. Manual of leaf architecture. New York: The New York Botanical Garden.

Fernandes, V.F., Thadeo, M., Dalvi, V.C., Marquete, R. \& Meira, R.M.S.A. 2016. Colleters in Casearia (Salicaceae): a new interpretation for the theoid teeth. Botanical Journal of the Linnean Society 181: 682-691.

Feild, T.S., Sage, T.L, Czniark, C. \& Iles W.J.D. 2005. Hydathodal leaf teeth of Chloranthus japonicus (Chloranthaceae) prevent guttation-induced flooding of the mesophyll. Plant, Cell and Environment 28: 11791190.

Fiaschi, P. \& Pirani J.R. 2005. Flora da Serra do Cipó, Minas Gerais: Araliaceae. Boletim de Botânica da Universidade de São Paulo 23: 267-275.

Flora do Brasil. 2020: Angiospermas. Disponível em http:// reflora.jbrj.gov.br/reflora (acesso em 20-VIII-2018). 
Gonzales, A.M. \& Tarragó, J.R. 2009. Anatomical structure and secretion compounds of colleters in nine Ilex species (Aquifoliaceae) from southern South America. Botanical Journal of the Linnean Society 160: 197-210.

Guilherme, F.C. 2011. Existe facilitação vegetal em campo rupestre sobre canga no Parque Estadual da Serra do Rola Moça, MG? Dissertação de Mestrado, Universidade Federal de Minas Gerais, Belo Horizonte.

Hickey, L.J. \& Wolfe, J.A. 1975. The bases of Angiosperm phylogeny: vegetative morphology. Annatomy Missouri Botanical Garden 62: 538-589.

Johansen, D.A. 1940. Plant Microtechnique. New York and London, McGraw-Hill Book Company INC.

Judd, W.S., Campbell, C.S, Kellogg, E.A., Stevens, P.F. \& Donoghue, M.J. 2009. Sistemática vegetal: um enfoque filogenético. $3^{\mathrm{a}}$ ed. Porto Alegre, Artmed.

Koulman, A., Lane, G.A., Christensen, M.J., Fraser, J. \& Tapper, B.A. 2007. Peramine and other fungal alkaloids are exuded in the guttation fluid of endophyte-infected grasses. Phytochemistry 68: 355-360.

Leitão, C.A.E., Meira, R.M.S.A, Azevedo, A.A \& Araújo, J.M. 2002. Ontogenia dos nectários extraflorais de Triumfetta semitriloba (Tiliaceae). Planta Daninha 20: 343-351.

Melo-de-Pinna, G.F.A. 2004. Anatomia foliar de Richterago Kuntze (Mutisieae, Asteraceae). Acta Botanica Brasilica 18: 691-600.

Nicolas, A.N. \& Plunkett, G.M. 2009. The demise of subfamily Hydrocotyloideae (Apiaceae) and the realignment of its genera across the entire order Apiales. Molecular Phylogenetics and Evolution 53: 134-151.

O'Brien, T.P., Feder, N. \& McCully, M.E. 1964. Polychromatic staining of plant cell walls by toluidine blue. Protoplasma 59: 368-373.

Paiva, E.A.S. 2012. Colleters in Cariniana estrellensis (Lecythidaceae): structure, secretion and evidences for young leaf protection. Journal of the Torrey Botanical Society 139: 1-8.

Shepherd, R.W. \& Wagner, G.J. 2007. Phylloplane proteins: emerging defenses at the aerial frontline? Trends in Plant Science 12: 51-56.

Silva, E.M.S., Hayashi, A.H. \& Apezzato-da-Glória, B. 2014. Anatomy of vegetative organs in Aldama tenuifolia and A. kunthiana (Asteraceae: Heliantheae). Brazilian Journal of Botany 37: 505-517.
Singh, S. 2014. Guttation: New Insights into Agricultural Implications. In: Sparks DL. Advances in agronomy. San Diego, Elsevier. pp. 97-135.

So, M.L. 2004. The occurrence of extrafloral nectaries in Hong Kong plants. Botanical Bulletin of Academia Sinica 45: 237-245.

Souza, V.C. \& Lorenzi, H. 2012. Botânica sistemática: guia ilustrado para identificação das famílias de fanerógamas nativas e exóticas no Brasil, baseado em APG III. Nova Odessa, Instituto Plantarum.

Souza, V.C., Flores, T.B., Colletta, G.C. \& Coelho, R.L.G. 2018. Guia de plantas do Cerrado. Piracicaba, Taxon Brasil.

Sperry, J.S. 1983. Observations on the Structure and function of hydathodes in Blechnum lehmannii. Americanfern Journal 73: 65-72.

Stevens, P,F. Angiosperm Phylogeny Website. 2001. Versão 14, Julho 2017, continuamente atualizado. Disponível em http://www.mobot.org/MOBOT/ research/APweb/ (acesso em 2-II-2017).

Takeda, F., Wisniewski, M.E. \& Glenn, D.M. 1991. Occlusion of Water Pores Prevents Guttation in Older Strawberry Leaves. Journal of the American Society for Horticultural Science 116: 1122-1125.

Thadeo, M., Cassino, M.F., Vitarelli, N.C., Azevedo, A.A., Araújo, J.M., Valente, V.M.M. \& Meira, M.S.A. 2008. Anatomical and histochemical characterization of extrafloral nectaries of Prockia crucis (Salicaceae). American Journal of Botany 95: 1515-1522.

Thadeo, M., Azevedo, A.A. \& Meira, M.S.A. 2014. Foliar anatomy of neotropical Salicaceae: potentially useful characters for taxonomy. Plant Syst Evol 300: 2073-2089.

Todzia, C.A. \& Keating, R.C. 1991. Leaf Architecture of Chloranthaceae. Annals of the Missouri Botanical Garden 78: 476-496.

Vasconcelos, V.V. 2014. Campos de altitude, campos rupestres e aplicação da lei da Mata Atlântica: estudo prospectivo para o estado de Minas Gerais. Boletim de Geografia 32: 110-133.

Vitarelli, N.C., Riina, R., Caruzo, M.M.R., Cordeiro, I., Fuertes-Aguilar, J. \& Meira, R.M.S.A. 2015. Foliar secretory structures in Crotoneae (Euphorbiaceae): diversity, anatomy, and evolutionary significance. America Journal of Botany 102: 833- 847. 